\title{
Endodontic Treatment Of Complex Curved Root Canal Maxilary Caninus : A Case Report
}

\author{
Ryan Mahardiansyah ${ }^{1, *}$, R. Tri Endra Untara ${ }^{2}$, Tunjung Nugraheni ${ }^{2}$ \\ ${ }^{1}$ Post Graduate of Conservative Dentistry Spesialistic Program, Faculty of Dentistry Gajah Mada \\ University \\ ${ }^{2}$ Department of Conservative Dentistry, Faculty of Dentistry Gajah Mada University, Yogyakarta, \\ Indonesia \\ *Coresponding author.Email : ryan.mahardiansyah@gmail.com, rtriendra@gmail.com, \\ drgtunjungnugraheni@ugm.ac.id
}

\begin{abstract}
One of the successful of the root canal treatment is biomechanical preparation. The successful key of the biomechanical preparation procedure is the early examination of curved root canal. The knowledge of curved root canal is being used to choose the right instrumentation. The biomechanical preparation of root canal can occured mistake such as ledge, perforation, and apical transportation are mistakes that frequently happen to the root canal curvature.Case Presentation. A 17 years old boy patient is being referenced to the Conservation Clinic of Dental and Oral Hospital of Faculty of Dentistry of University of Gajah Mada with a complaint that his front teeth is broken. The patient had a history that he fell from a motorcycle 3 weeks ago. The thermal test and EPT shows that the 13 teeth is non-vital. The 13 teeth diagnosis is pulp necrosis. The periapical radiographs image shows a curved root canal (J-shaped). The 13 teeth received root canal treatment by using precurved file and flexible file to follow the curved root canal. The root canal filling is using backfill system with gutta percha and sealer epoxy. The patient is being controlled regularly and after one month without any complaint.Conclusion. The knowledge about root canal anatomy, instrumentation technic, and root canal filling is so important to the successful of the root canal treatment.
\end{abstract}

Keywords: Curvature, Pre-curve files, Glide path

\section{INTRODUCTION}

Cleaning and shaping of the root canal systems is the success key of endodontic therapy. It depends on those factors. As for chemo-mechanical preparation, it needs proper assessment of the root canal curvature. This is essential. In root canal curvature radius, selecting the suitable NiTi rotary files and bring forward fitted plan of root canal instrumentation. Doing the biomechanical preparation is not easy. Sometimes there are a few of procedural errors while preparing curved canals, such perforations and apical transportations, blockages, and ledge formation. A lot of authors had their opinion about the instrumentation while preparing curved canals. They wrote that it might cause formation of the ledges, loss of working length, perforations and apical transformation, also blockage of the apical third. They recommend using flexible NiTi files or precurve files can reduce the prodecural mistake [1].

Some of them said that the Schneider's technique underlined the canal curvature in coronal area.
Meanwhile Hankins who describe long axis technique thinks that the apical curvature and didn't assess whole root curvature [2,3]. Sonntag gives recommend the morphology and anatomy of the root canal can be detected by a preoperative radiograph that took in 20 degree mesial or outlying projection. It is important to decide the canal curvature because it will enable the maintenance of the taper shape and prevent the structural damage of the endodontic instruments $[5,6]$. There is another method that considered as the most effective and fit than other methods. This method was presented by Gunday which root curvatures is determined with measure the canal access angle. Straight 5 degree, moderate 10 to 20 degree, and severe 25 to 70 degree was named based on the degree of the curvature $[7,8]$.

\section{CASE PRESENTATION}

A 17 years old boy patient is being referenced to the Conservation Clinic of Dental and Oral Hospital of Faculty of Dentistry of University of Gajah Mada with a complaint that his front teeth is broken. The patient 
had a history that he fell from a motorcycle 3 weeks ago. The medical history revealed the patient was absence of any systemic disorders. Extraoral examination was revealed no significant findings. Intraoral examination showed vitality test was positive response, percussion and palpation was also positive response. The crown of right maxillary caninus was fractured that involved the incisal third with small exposure of the pulp.The thermal test and EPT shows that the caninus teeth is non-vital. The caninus diagnosis is pulp necrosis. The periapical radiographs image shows a curved root canal (J-shaped). The prognosis was good and it was decided to perform pulpectomy and permanent restoration with direct composite resin.

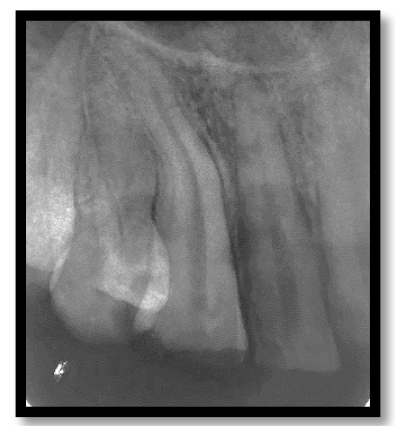

Figure 1. Periapical radiograph showing tooth 13 with curve root canal

\section{CASE MANAGEMENT}

The treatment that had been done was gave the local anesthesia with lidocaine $2 \%$., insolation using rubber dam, then to follow the canal curvature it needs an intermediate and flexible file and use smaller number. Size 10 K-type file was being used to explore and discover the canal and it moves slowly to it. By using radiograf and an apex locator, the root canal length can be noted.

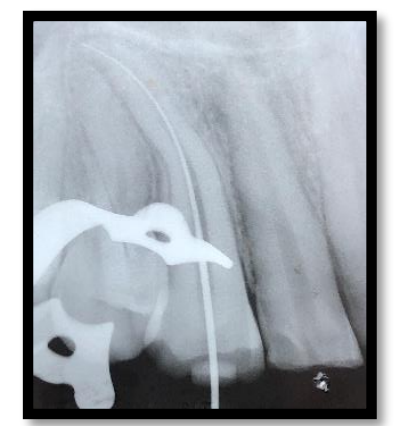

Figure 2. Periapical radiograph showing working length $28 \mathrm{~mm}$

Edta gel was used to make the mechanical glide path to act as a lubricate with NiTi rotary device. There are one devices $17.02 \%$ of the helical angle. The order was the $17.02 \%$ being used after the size $10 \mathrm{~K}$-type file to set up the root canal to full WL. It continues with an endodontic engine being used all glide path with 2.2
$\mathrm{N} / \mathrm{cm}$ torque and $300 \mathrm{rpm}$. Then after each device it continues with $30-\mathrm{G}$ needle syringe with a $5 \mathrm{ml}$ of $2,5 \%$ of $\mathrm{NaOCl}$. And the move forward that the biomechanical preparation was completed. It was completed using endoedge file in the following order $17.04 \%, 23.04 \%$, and lastly $30.04 \%$ afterwards the canal was irrigated with sodium hypochlorite, sodium chlorite, and chlorhexine gluconate. And this was done by swill it with $17 \%$ EDTA. The root canal filling is using backfill system with gutta percha and sealer epoxy.
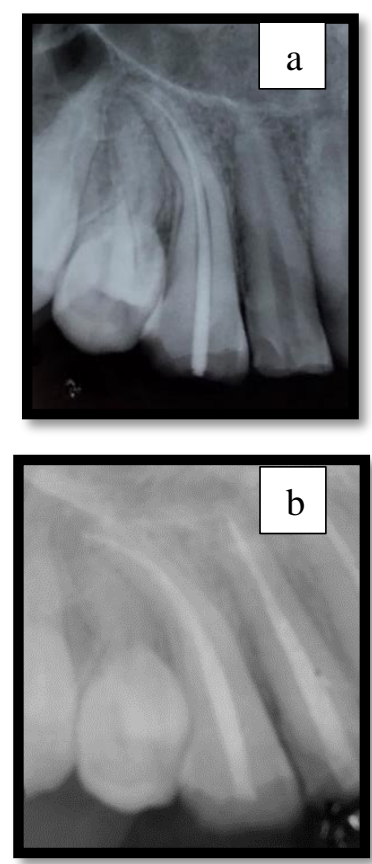

Figure 3 a. Periapical radiograph of master cone b. Periapical radiograph after obturation

The patient was reviewed one week after root canal treatment and reported no symptom. Radiograph was showed good apical sealing and no periapical infection. Alginate impression was applied to both upper and lower teeth to get the mock-up model. Wax-up model was made for 13,12,11 and 21 teeth model using wax. Afterwards, silicon index was made using putty and was placed on palatally 13,12, 11 and 21 model that has been wax-up-ed before. Direct composite resin restoration was performed that involve intracanal retention with fiber reinforced post. Root canal was measured that $4 \mathrm{~mm}$ gutta percha was remained from the apical. Gutta percha was removed by peeso-reamer and the canal was irrigated using saline. Size of fiber post was selected consider by size of peeso reamer that the last one has been used. The canal was etched using phosphoric acid $37 \%$ while the fiber reinforced canal was etched with hydrofluoric acid. Bonding was applied into the canal and then was cured 20 seconds. Silane was applied onto fiber post and then was cured 20 seconds. Resin cement was mixed and placed into the root canal with mixing tip. Immediately fiber post was putted into root canal and cure with light curing unit for 20 seconds. Core built-up was performed by 
resin cement that was mixed on paper pad using plastic instrument. Shade matching was done with A3 dentin shade and A3 enamel was selected for the case. The enamel were beveled by flame shape burs with hollowground bevel type was selected .Tooth13,12, 11 and 21 was thoroughly rinsed and etched using phosphoric acid 20 seconds for enamel and 10 second for dentin. The phosphoric acid was cleaned by water spray and dried using air-water-syringe. Bonding was applied onto enamel and dentin surface and was cured for 20 seconds. First layer or palatal shell approximately $1 \mathrm{~mm}$ thickness was created on palatal using translucent A3 enamel shade (Z350XT-3M) that was placed on silicon index and was cured for 20 seconds. Both mesial and distal proximal wall was created using celluloid strips and A3 enamel shade (Z350XT-3M). The A3 dentin shade (Z350XT-3M) composite resin was inserted for the next layer to reproduce the dentin and mammelons structure. The A3 body shade (Z350XT-3M) was applied on middlefacial area, afterward the A3 enamel shade (Z350XT$3 \mathrm{M})$ was combined and placed incisally to get the haloeffect from the restoration. Each composite resin layer was cured for 20 seconds. The restoration surfaces were finished with finishing disc (soflex-3M) and finishing burs. Polishing step was done with diamond impregnated polishing burs (Diacomp twist plus, EVE).
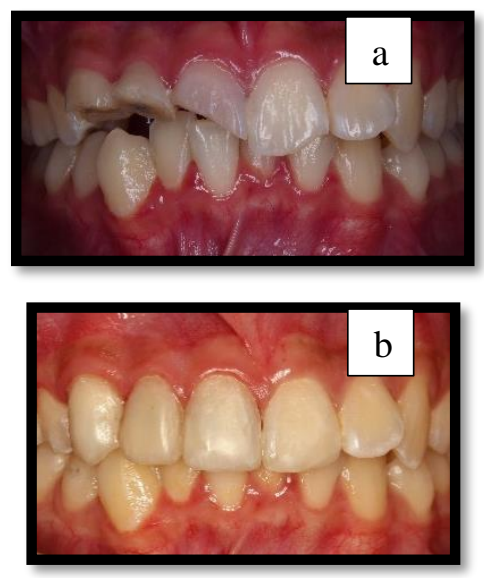

Figure 4. (a) clinical appereance before treatment; (b) week composite resin restoration on 13,12,11 and 21 teeth

\section{DISCUSSION}

It was a challenge itself to maintain the original shape of the canal and also keeping away the canal diversion especially when prepare curved root canal severely. Handpreflaring with K-file made the coronal and apical curves more streamlining than the manual Kfile with preflaring. It was claimed that the nickeltittanium device was more effectively than stainlees steel device to shape the root canal. It is because they had 2 or 3 times of the flexibility [9]. The used of NiTi rotary gave a quite advantage. It was not only make the initial removal of pulp tissue and debris from the root canal be better, but also resist the clinician working length and patency of root canal [10]. Many kinds of glide path devices has been launch for the preflaring of the curved root canal such as Flex Glide files, NiTi Scout Race, G-File system, Xplorer files, Proglider, Path File, Hyflex Glide Path files, and Race ISO 10. All of these files have a different variation so the glide path prepared will not be similar [11].

The first step in the root canal treatment is prepare glide path. This need to be done because to make sure that a straight line can access to the root canals. K-File with size 06,08 , or 10 made by stainless steel can be used to precurved the root canal with manual technique. The rotary glide path device cannot be carry on if the initial glide path had not up to size K-file 10 . It can be carry on when the K-file 10 put in until working length then withdrawn $1.5 \mathrm{~mm}$ by hand and push back to working length without difficulty. After this then the rotary glide path device is allow to be used. As the fulfillment of glide path, the canal must kind of big or as the size of the first rotary that being used to prepare the root canal.

In today's case, it was being told that canal modification and aberrations reduced because the glide path is performed previously. But other had different opinion such as Burklein. In his study he said that glide path preparation did not had the impact and significant result [12].

\section{CONCLUSION}

The success key of endodontic treatment is the knowledge of root canal anatomy, the device techniques, and the root canal filling.

\section{REFERENCES}

[1] Zhu YQ, Gu Y, Du R, Li C (2003) Reliability of two methods on measuring root canal curvature. Int Chin J Dent 3: 118-121.

[2] Abou-Rass M, Frank AL, Glick DH (1980) The anticurvature filing method to prepare the curved root canal. J Am Dent Assoc 101(5): 792-794.

[3] Hankins PJ, ElDeeb ME (1996) An evaluation of the Canal Master, balanced force, and step-back techniques. J Endod 22 (3): 123-130.

[4] Sonntag D, Stachniss-Crap S, Stachniss V (2005) Determination of root canal curvature before and after canal preparation (part I): a literature review. Aust Endod J 31(3): 89-93.

[5] Segal M (2008) Managing Curved Canals: the Straight-Away and Super Glide Path Technique. Inside Dentistry 4(4).

[6] Gunday M, Sazak H, Garip Y (2005) A comparative study of three different root canal curvature measurement techniques and measuring the canal access angle in curved canals. J Endod 31(11): 796-798.

[7] Sakkir N, Thaha KA, Nair MG, Jospeh S, Christalin R (2014) Management of Dilacerated and S-shaped 
Root Canals - An Endodontist's Challenge. J ClinDiagn Res 8(6): ZD22-ZD24.

[8] Schilder H (1974) Cleaning and shaping the root canal. Dent Clin North Am 18(2): 269-296.

[9] Schafer E, Diez C, Hoppe W, Tepel (2002) Roentgenographic investigation of frequency and degree of canal curvatures in human permanent teeth. J Endod 28(3): 211-216.

[10] Bürklein S, Schäfer E (2013) Critical evaluation of root canal transportation by instrumentation. Endod Topics 29(1): 110-124.

[11] Hamasha AA, Al-Khateeb T, Darwazeh A (2002) Prevalence of dilacerations in Jordanian adults. Int Endod J 35(11): 910-912.

[12] Bogle J (2013) Endodontic Treatment of Curved Root Canal Systems. Oral Health 103. 